\title{
Domains of Archean mantle lithosphere deciphered by seismic anisotropy - inferences from the LAPNET array in northern Fennoscandia
}

\author{
J. Plomerová, L. Vecsey, V. Babuška, and LAPNET Working Group \\ Geophysical Institute, Academy of Science of the Czech Republic, Boční II/1401, 14131 Prague, Czech Republic
}

Received: 10 June 2011 - Published in Solid Earth Discuss.: 20 July 2011

Revised: 15 November 2011 - Accepted: 17 November 2011 - Published: 15 December 2011

\begin{abstract}
An international LAPNET array (20072009, http://www.oulu.fi/sgo-oty/lapnet) of the POLENET/LAPNET sub-project of the POLENET-IPY consortium, related to seismic and geodetic studies in the Arctic regions, consisted of about 60 broadband seismic stations located on the territory of northern Finland and adjacent parts of Sweden, Norway and Russia. We analyze relative $\mathrm{P}$-wave travel-time deviations evaluated for a subset of 90 teleseismic events recorded by the LAPNET array and show examples of lateral variations of shear-wave splitting to demonstrate variability of fabrics of the Archean mantle lithosphere. The initial results clearly demonstrate the Archean mantle lithosphere consists of domains with consistent fabrics reflecting fossil anisotropic structures. 3-D self-consistent anisotropic models with inclined symmetry axes accommodate two independent sets of body-wave anisotropic observations. Individual domains are delimited by boundaries (sutures), where the anisotropic parameters change. The results obtained from the LAPNET array fill a gap in structural studies of the upper mantle beneath northern Fennoscandia.
\end{abstract}

\section{Introduction}

The Svecofennian domain forms the largest part of the Proterozoic provinces of the Fennoscandian Shield (Fig. 1) in its south-western part, while most of its eastern part is of the Archean age. Island arcs began to form at the periphery of the Karelian craton in the Paleoproterozoicum, and several suspect terranes (micro-continents) were attached during accretionary orogeny (Snyder, 2002). The shield is characterized by a thick lithosphere (Plomerová et al., 2008) with a

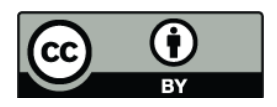

Correspondence to: J. Plomerová (jpl@ig.cas.cz) thick topographically uncompensated crust (Luosto, 1997). Korja et al. (2006) suggest that changes in orientation of the Moho depth isolines indicate terrane boundaries within the Fennoscandian Shield, the finding being supported by the existence of dipping wide-angle mantle reflections. Complex tectonic history of Precambrian Fennoscandia is comparable with tectonics of Phanerozoic Europe, in which many processes operated simultaneously and changed abruptly.

The main target of the POLENET/LAPNET sub-project of the POLENET-IPY consortium is to carry out a multidisciplinary research based on a temporary broadband seismic array deployed in the area of northern Finland and adjacent parts of Sweden, Norway and Russia. The international array (Fig. 1) recorded teleseismic, regional and local events during May 2007-September 2009 for structural studies in northern Fennoscandia. Recordings of glacial earthquakes are of particular interest as well (Poutanen and Ivins, 2010; Kozlovskaya et al., 2011). The research benefiting from the LAPNET array aims at obtaining a 3-D seismic model of the crust (Silvennoinen et al., 2011) and upper mantle down to $670 \mathrm{~km}(\mathrm{P}-$ and S-wave velocity tomography models, positions of major boundaries in the crust and the upper mantle, and estimates of seismic anisotropy strength and orientation) in the northern Fennoscandian Shield, particularly beneath the Archean domain of Fennoscandia. The 3-D model can be used to define spatial distribution and depth of the Archean lithosphere for different purposes, e.g., for diamond prospecting. The 3-D model of the crust and the upper mantle will also be used to improve registration and location of local earthquakes and understanding mechanisms of local seismicity in northern Fennoscandia (e.g., Uski et al., 2006).

Pioneering tomographic studies of the European upper mantle (Aki et al., 1977) provided rough images of its velocity structure, where regions with subducting lithosphere appear as high-velocity heterogeneities in Phanerozoic provinces. As expected, no distinct regional variations in isotropic velocities within the upper mantle were detected

Published by Copernicus Publications on behalf of the European Geosciences Union. 


\section{POLENET/LAPNET}

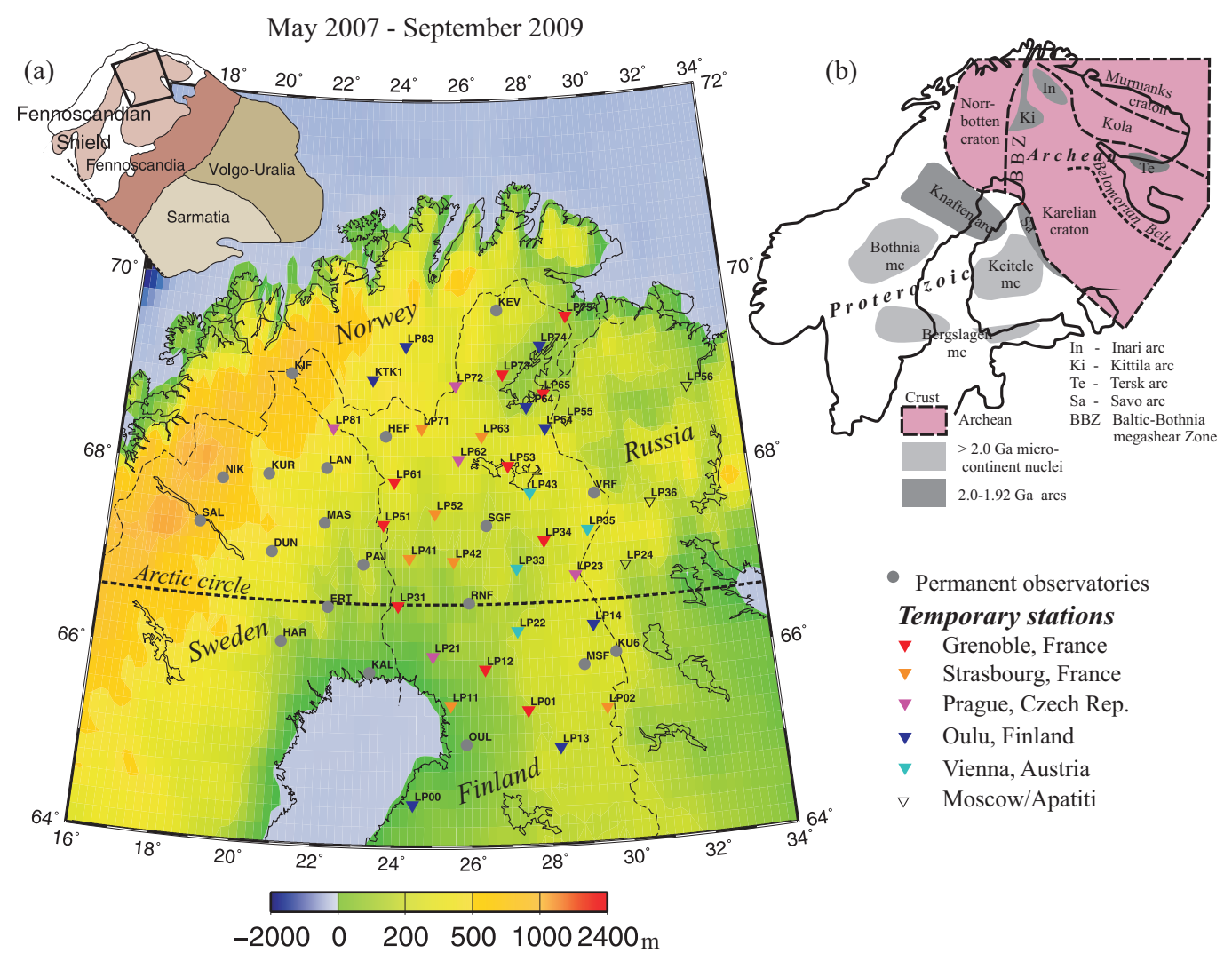

Fig. 1. POLENET/LAPNET network of broad-band seismological stations (a) and micro-continental nuclei (mc), island arcs and boundaries of hidden and exposed suspect terranes in the Fennoscandian Shield older than $1.92 \mathrm{Ga}$ (b), (redrawn according to Korja et al., 2006).

in the Precambrian region since then, neither on a European scale (Amaru et al., 2008), nor in regional tomography studies based on data of temporary arrays in several regions of Fennoscandia (e.g., Plomerová et al., 2001; Sandoval et al., 2004; Shomali et al., 2002; Eken et al., 2007, 2008). The most significant velocity changes in the upper mantle beneath Precambrian provinces can be related to lateral changes of depth of the lithosphere-asthenosphere boundary (Calcagnile 1991; Cotte et al., 2002; Plomerová et al., 2002, 2008, 2010; Olsson et al., 2007). On the other hand, studies of fossil anisotropy in most of Fennoscandia (except of its northern part) allowed us to map individual domains of mantle lithosphere with their own consistent fabrics. The domains differ in orientation of symmetry axes, their dips and sometimes also in symmetry of olivine aggregates approximating the structures (Plomerová et al., 2001, 2002, 2006; Vecsey et al., 2007). The retrieved 3-D self-consistent anisotropic models of the mantle lithosphere are delimited by boundaries/transitions which correlate with surface traces of dominant sutures or distinct tectonic faults, e.g., the TransEuroperan Suture Zone, the Protogene zone in south central Sweden, the Proterozoic-Archean contact zone in southern
Finland, and boundaries between Svecofennian domains in Sweden (Eken et al., 2011).

Similarly to the most of large passive seismic experiments in Europe (e.g., CALIXTO, EIFEL, PASSEQ, RETREAT), this paper aims at presenting first results on seismic anisotropy of the mantle lithosphere obtained from the LAPNET array body-wave data processed in 3-D. The results are robust enough with general consequences for tectonic development of cratonic provinces and are supposed to fill a gap in studies of velocity structure of the upper mantle beneath northern Fennoscandia (e.g., Sandoval et al., 2004; Pedersen et al., 2006; Plomerová et al., 2006, 2008; Vecsey et al., 2007; Eken et al., 2010).

\section{Data of the POLENET/LAPNET array and methods}

The international LAPNET array consisted of 37 temporary broadband stations and 20 permanent broadband observatories operated in northern Fennoscandia (Fig. 1). Most of the stations were located north of the Arctic Circle, which made their servicing a difficult task, especially during the winter time. The array was active in a period from May 2007, when 
most of French stations were deployed, to September 2009, when temporary stations of the Czech pool were dismounted. Different instrumental equipments were spread over the region in such a way that the stations covered the territory homogeneously as to their spacing of about $70 \mathrm{~km}$, on average, and also as to the instrument types. The reason was to avoid a potential systematic waveform distortion that could concentrate in a part of the region. The two-year passive experiment resulted in archiving $740 \mathrm{~Gb}$ of continuous recordings, which are now at stage of additional testing and processing.

In this study we present results of P-wave travel-time deviations evaluated for a set of 90 teleseismic events recorded by the LAPNET array and examples of lateral variations of shear-wave splitting, to demonstrate a variability of the Archean mantle lithosphere fabric. Even if our data is not complete, the P-wave residual set is well comparable, if not larger, with number of events in several recent regional tomography studies of the upper mantle (e.g., Ritter et al., 2001; Shomali et al., 2002, 2006; Eken et al., 2007; Mitterbauer et al., 2011). To study P-wave travel-time deviations, we picked arrival times on individual recordings simulating the WWSSN response, using of recently developed semiautomatic software based on the Seismic Handler software (Stammler, 1993). The software allows us to measure times of the first extremes correlated across the array and to calculate $\mathrm{P}$-arrival times at individual stations. Applying this software resulted in $\sim 50 \%$ decrease of standard deviations of the travel-time residuals in comparison with a manual picking or implementation of other semi-automatic pickers tested (e.g., Rawlinson and Kennett, 2004).

To study large-scale anisotropy of the upper mantle, we first apply crustal corrections to account for effects of Mohodepths and crustal-velocity variations. Travel time along each ray is corrected for time spent in the model of the crust by Grad et al. (2009) relative to the IASP91 model. Particularly the Moho-depth variations might appear as heterogeneities in the large-scale characteristics of the residual pattern. By subtracting an event travel-time mean, we deal with relative residuals and through additional normalization of the relative residuals, in which the directional means representing average velocity beneath each station are subtracted, we then analyze directional terms of relative residuals at individual stations of the array. For details of the method we refer to, e.g., Babuška and Plomerová (1992). We map distribution of stations with similar distributions of these azimuthincidence angle dependent terms, which we plot in polar projections of the lower hemisphere ( $P$ spheres) to describe the three-dimensionality of the phenomenon. To locate changes in orientation of seismic anisotropy, i.e., the mantle fabric, we search for lateral changes in the general pattern of the $\mathrm{P}$ spheres. The changes often occur in vicinity of prominent tectonic boundaries, which belong to characteristics allowing us to relate the phenomenon to fossil anisotropy in the mantle lithosphere (Babuška and Plomerová, 2006, for review). Neither small-scale heterogeneities, which would appear as small isolated inconsistencies in the general P-sphere pattern, nor a contribution from crustal anisotropy can substantially affect the observed mantle anisotropy bearing in mind the wave lengths we deal with.

To confirm the existence of the upper mantle anisotropy beneath the Shield, we analyze splitting parameters of shear waves refracted at the core-mantle boundary (SKS), using the SPLIT software (Vecsey et al., 2008; http://www.ig.cas. cz/en/personal-pages/ludek-vecsey/split/). The software enables us to evaluate the shear-wave splitting in 3-D; and thus, by inverting variability of the splitting parameters (the fast $S$ polarization direction and split delay time $\delta t$ ) along with sensitivity of the P-wave anisotropic parameters on the backazimuths and angles of propagation within the upper mantle, to infer anisotropic structures with generally oriented (dipping) symmetry axes. At this stage of the research, we invert the P-wave anisotropic parameters separately and analyse jointly the two independent datasets to retrieve preliminary 3-D self-consistent anisotropic models of the mantle lithosphere which fit both types of body waves. In the P-sphere inversion, we search for orientation of peridotite aggregates to fit the observed variation of the directional terms of relative residuals (Š́lený and Plomerová, 1996). We mainly concentrate on a search of boundaries of the Archean mantle lithosphere domains which exhibit a uniform anisotropy. After accumulating sufficient amount of shear-wave anisotropic parameters, we will invert the body-wave anisotropic parameters jointly to get self-consistent anisotropic models of the Archean part of the Fennoscandian mantle lithosphere.

\section{Observed body-wave anisotropy}

The northern part of Fennoscandia is well-situated relative to teleseismic earthquake foci. Thus, even the subset of 90 events analyzed at most of stations up to now provided a good azimuthal coverage of rays at most of the stations. Stations with similar distribution of relatively early and delayed travel times form groups with their characteristic P-sphere patterns (Fig. 2). The so called "bipolar pattern" (e.g., Babuška and Plomerová, 2006), used for P spheres, in which an azimuth (+180) approximately separates the delayed and earlier propagations, is observed at the majority of analysed stations. The stations with consistent "bipolar pattern" form three distinct regional groups in the northern and west-central parts of the array. The directional terms of the residuals lie in the interval $(-0.5 \mathrm{~s}, 0.5 \mathrm{~s})$. We associate the bipolar pattern with the P-wave propagation through structures of the mantle lithosphere characterized by different azimuths in which the high- or low-velocity directions incline. Anisotropy with horizontal symmetry axes does not produce the observed "bipolar pattern" - the early and delayed residual terms in the opposite half of the P spheres (Babuška et al., 1993) - though even these simplified structures were used to correct the $\mathrm{P}$ delays used in the upper mantle tomography (O'Driscoll et al., 2011). 
We infer the convergently dipping high-velocity directions beneath stations in the northern part of the array (Fig. 2, Domains 1 and 2 in the east, with about westerly dipping high velocities versus Domain 3 in the west, with easterly dipping high velocities). In the central part of the array, no pattern dominates in the east (Domain 5), while the high velocities dipping to the NE characterize stations in the west (Domain 4), following thus by about $90^{\circ}$ rotated pattern of the stations further to the north (Domain 3) where the high velocities dip to the SE. Only two stations in the southern part of the array (MSF and KU6) exhibit the distinct bipolar pattern similar to that of stations in the NW corner of the array (Domain 3). Further to the southwest, "no P pattern" prevails at most of stations (except for a weak, but not a bipolar pattern at station OUL). In general, the upper mantle, particularly the mantle lithosphere, beneath the Archean part of Fennoscandia exhibits distinct anisotropic characteristics in P-wave propagation in the north, while the mantle beneath the southeastern part of the LAPNET array does not have a distinct anisotropic pattern. However, detecting no anisotropic signal does not exclude a presence of anisotropy in the upper mantle, but might also reflect a complicated structure resulting in annulling the anisotropic signal observed at the surface (see Fig. 5 and Vecsey et al., 2007).

The shear-wave splitting, analogical to the light birefringence in optics, is considered as evidence that the waves propagate through an anisotropic medium. Orientation of the fast split shear-wave polarization and the time delay of the split slow-shear wave determine an orientation and intensity of the anisotropy. To model realistic 3-D anisotropic structures of the upper mantle, we need to analyze a large number of shear-wave splitting polarizations and delay times for a large variety of directions of propagations. However, to demonstrate changes of the structure for different provinces, we examine geographical variations of the two anisotropic splitting parameters evaluated for an event. Distinct variations of polarization directions, as well as of delay times, were detected across the LAPNET array (Fig. 3). Stations with similar splitting parameters, evaluated for waves with easterly back-azimuths, form groups almost identical with those delimited by a resemblance of the P-sphere patterns, with null (LP51) or a weak splitting (LP71, LP61) along the domain boundaries (e.g., Plomerová et al., 2001).

\section{Modelling the mantle lithosphere domains delimited by body-wave anisotropy}

It is evident that, thanks to the good azimuthal coverage of Pwave data set and clear geographical variations in shear wave splitting evaluated for two events, already at this stage of our research based on the LAPNET data, we can claim that also the Archean mantle lithosphere of northern Fennoscandia consists of several domains with their own fabrics. Both the sharpness of boundaries of the domains mapped according to changes of the anisotropic body-wave parameters, and the correlation between the mantle boundaries and dominant tectonic sutures on the surface, justify us to associate the observed anisotropy with fossil preferred orientation of olivine in the mantle lithosphere. Generally accepted weak asthenosphere flow beneath cratons could hardly produce such abrupt changes observed beneath the shield (Vecsey et al., 2007; Eken et al., 2010; Wüstefeld et al., 2010). For the first simple estimates of the lithosphere domain fabrics, we invert the P-spheres for the symmetry axes orientation and calculate synthetic shear-wave splitting parameters for a comparison with the observed ones (Fig. 4). Thickness of the mantle lithosphere domains is set to $100 \mathrm{~km}$, according to the LAB depth estimates by Plomerová and Babuška (2010). The authors define the lithosphere-asthenosphere boundary as a transition between the fossil anisotropy within the mantle lithosphere and anisotropy related to the presentday flow in the underlying mantle, also detectable in surfacewave polarization (radial) and azimuthal anisotropy (Plomerová et al., 2002; see also Gung et al., 2003). We model anisotropic structures of the lithosphere domains by two types of peridotite aggregates: $a$ with hexagonal symmetry and the dipping (high-velocity direction), or $b$ symmetry axes with strength of anisotropy $\sim 5 \%$ (low-velocity direction). The $a$-axis model represents an approximation of the orthorhombic symmetry. Such models comply with directional variations of anisotropic parameters at individual stations and, moreover, explain a seeming discrepancy between the average fast shear-wave polarizations and the highvelocity directions from the P-residuals spheres in several regions. Already Babuška et al. (1993) showed the fast S polarizes along the strike of the $b$-axis models, i.e., along the strike of the dipping high-velocity foliation plane $(a, c)$, resulting thus in about perpendicular orientation of the dipping high P-wave velocities and azimuthal polarizations of steeply incident shear waves (see Domain B in Fig. 5a).

There are four groups of LAPNET stations with distinct Ppattern that can be inverted for the mantle lithosphere fabric (Table 1). The $b$-axis models accommodate the body-wave observations in the northern part of the LAPNET array, with the westerly dipping high-velocity $(a, c)$ foliations in the east and easterly dipping foliations in the west, satisfying the predominantly southward pointing fast shear-wave polarizations. As expected, the mantle structure in the middle part of the LAPNET array, around the Proterozoic-Archean mantle lithosphere contact, is more complicated (Plomerová et al., 2006). While the short-period $P$ waves detected anisotropy in the west and 'no anisotropy' in the east of the central part of the array, the broad-band shear-wave splitting is weak on the west (Fig. 3), but it is distinct in the eastern rim of the LAPNET array. This "paradox" is reflected also in the preferred $a$-axis model of the Group 4 (Table 1), which seems to fit the broad-band shear wave observations everywhere in the central part of the array, i.e., also in its eastern part. Nevertheless, the decrease of intensity of the anisotropic signal 


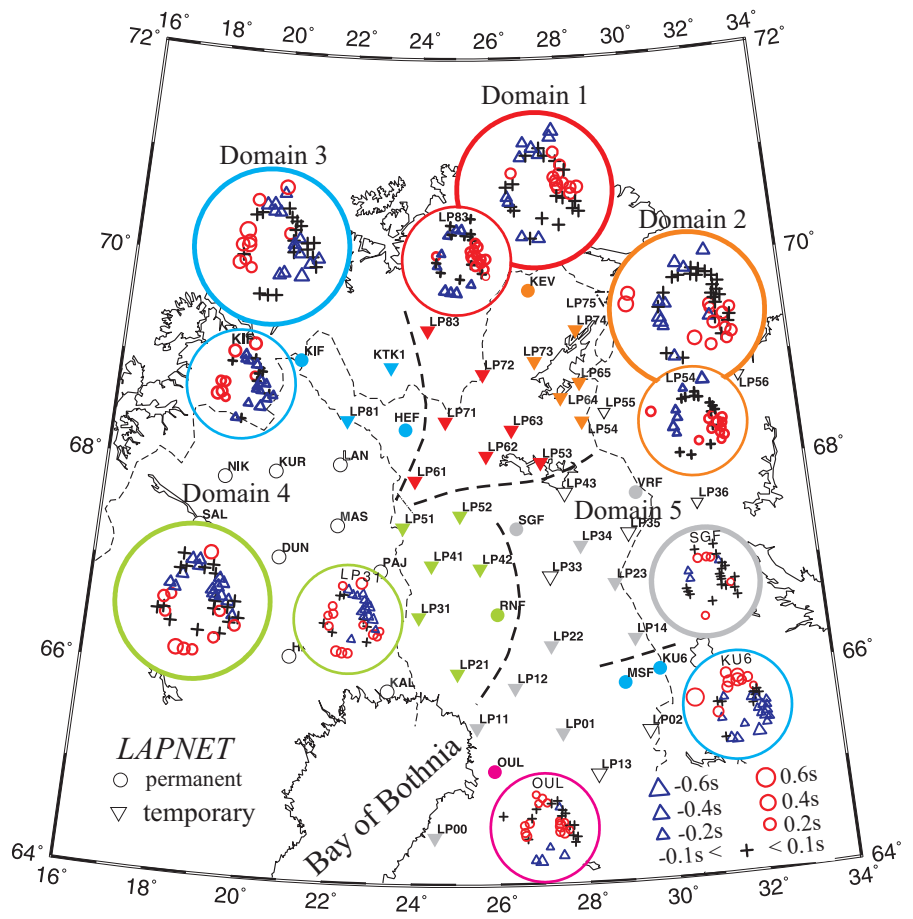

Fig. 2. Stations clustered into domains according to similarity of distribution of early and delayed travel times relative to a directional mean at each station, calculated from relative residuals corrected for crustal effects. The P spheres show smoothed azimuth-incidence angle dependent terms for representatives of each group and those calculated from all stations included in each group (marked by different colours). Thick dashed lines mark schematically the domain boundaries.

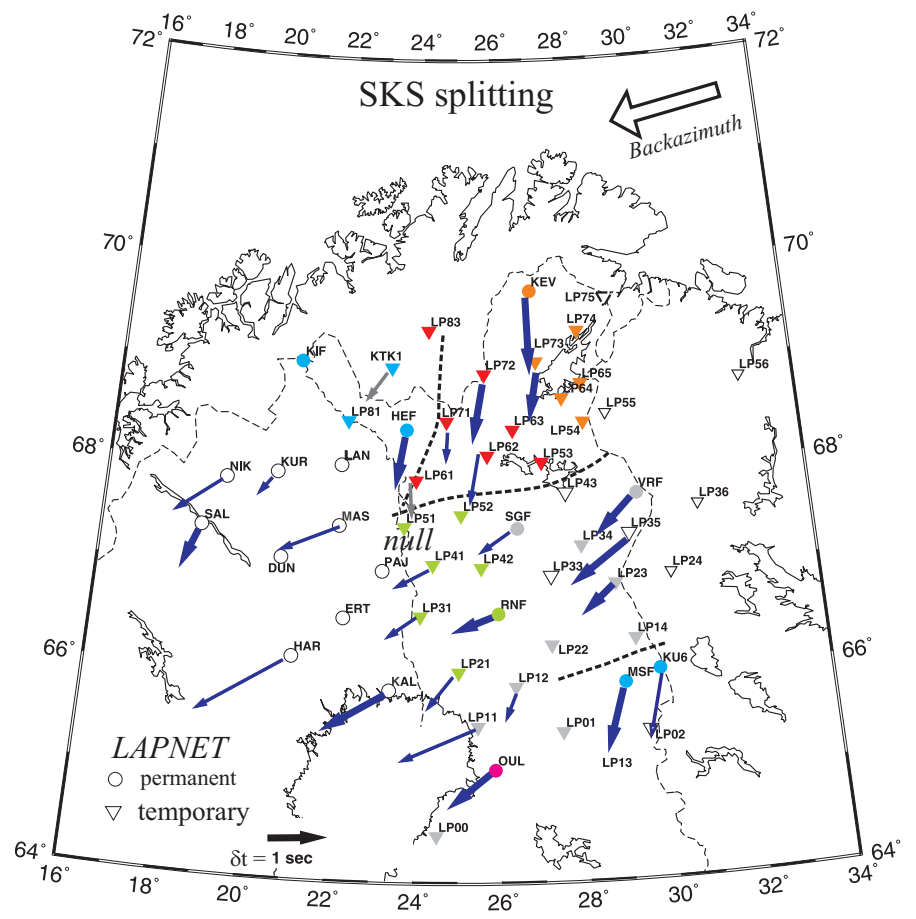

2008/08/04 20:45:14.0 5.91S 130.19E, depth 173km, Mw 6.1, BANDA SEA

Fig. 3. Geographical variations of fast shear-wave polarizations and split delay times for an event that occurred on 2008/08/04 with epicentre beneath the Banda Sea region. The arrows mark azimuths of fast S-wave polarizations and point in their dip directions in the Q-T planes in the ray parameter co-ordinating system (Vecsey et al., 2008). Stations with similar fast S polarizations and split delay times form groups like those determined from P-spheres (station in the same colours as in Fig. 2). Anisotropic signal of shear wave decreases or disappears (null split) at stations close to domain boundaries (schematically marked by the thick dashed lines). Good, firm and poor splitting measurements are marked by thick, thin and empty-head arrows, respectively. 


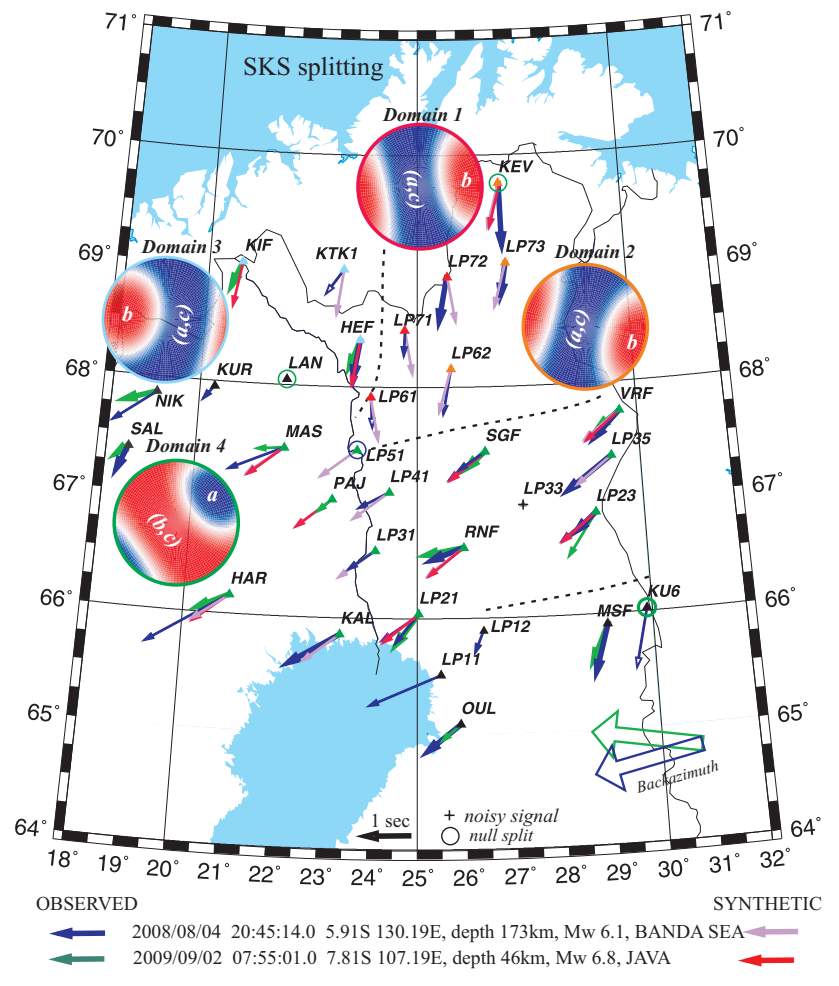

Fig. 4. Observed and synthetic shear-wave splitting for two events with easterly back-azimuths modelled according to results of the P-sphere inversions with modified inclination of symmetry axes (see Table 1). Stations (triangles) are coloured according to the anisotropic model used. Thick dashed lines delimit the domains whose structure is approximated by different models. Anisotropic aggregates with divergently dipping high-velocity $(a, c)$ foliations (the $b$-axis models) approximate the lithosphere fabric beneath the northern part of the LAPNET array, whereas in the central part a model with steeply dipping lineation $a$ (the $a$-axis model) fit the observed shear-wave splitting and $\mathrm{P}$-wave anisotropic parameters (in its western part).

from the east to the west (Fig. 4) in the central band of the LAPNET array and a similarity of the retrieved anisotropic model with the model (Fig. 6) derived for the Archean part of the shield south of the LAPNET array (Vecsey et al., 2007) allows us to consider this tentative model as characterizing the fabrics of the Archean mantle lithosphere east of the complicated contact with the Proterozoic provinces on the west.

Though the azimuthal coverage of analyzed $P$ waves is adequate to retrieve azimuths $\phi$ of the symmetry axes in the inversions reliably, angles of axis inclinations $\theta$ (measured from vertical) are less well resolved. This is also reflected in small split delay times calculated for the P models in Table 1 (calculated delays $\delta t \sim 0.01-0.04 \mathrm{~s}$ vs. observed delays $\delta t \sim 0.8 \mathrm{~s}$ ), especially at domains where the shear wave propagates close to the symmetry axis (Domain 1 and 2, cf. with backazimuth in Fig. 3). Vecsey et al. (2011) showed that $\delta t$ $\leq 0.3$ s, i.e., often considered as null splitting due to noise
Table 1. Anisotropic models retrieved by the P-sphere inversion, along with modifications of inclination angle to fit the shear-wave splitting.

\begin{tabular}{llllllll}
\hline & \multicolumn{9}{c}{ Original inversion } & \multicolumn{2}{c}{ Modified } \\
Region & P-model & $\theta^{\circ}$ & $\phi^{\circ}$ & $H(\mathrm{~km})$ & $v_{P}\left(\mathrm{~km} \mathrm{~s}^{-1}\right)$ & $\theta^{\circ}$ & $\phi^{\circ}$ \\
Domain 1 & $b$-axis & 25 & 80 & 100 & 8.1 & 80 & 80 \\
Domain 2 & $b$-axis & 30 & 105 & 100 & 8.1 & 80 & 105 \\
Domain 3 & $b$-axis & 60 & 275 & 100 & 8.3 & 60 & 280 \\
Domain 4 & $a$-axis & 15 & 55 & 100 & 8.5 & 70 & 55 \\
\hline
\end{tabular}

$\phi \quad=$ azimuth of the symmetry axis measured from the North

$\theta \quad=$ angle of inclination of the symmetry axis measured from vertical upward

presented in real signals, is evaluated for rays in a cone as broad as $40^{\circ}$ centred around the symmetry axis. Therefore, we modified the angles $\theta$ (Table 1) to get better fit between the synthetic and observed splitting parameters (Fig. 4). The steeply inclined $(a, c)$ foliations in the northern part of the array and gently inclined lineation in the central part of the array mimic well the observed shear-wave splitting for two teleseismic events with easterly back-azimuths. Such steep fabrics in the shield areas were also inferred from the radial and azimuthal anisotropy of surface waves (Babuška et al., 1998).

\section{Discussion}

Sensitivity of different waves on orientations of domain fabrics and their changes strongly depends on wave lengths and on particle motions. The "null" shear-wave splitting (e.g., at station LP51, see Figs. 1 and 3) and significant reduction of split delay times (e.g., at stations LP71 and LP61) can reflect the sub-vertical propagation of the shear wave close to a steep mantle boundary separating two lithosphere domains with different fabrics, both sampled by the same longperiod wave (Fig. 5). Wavelengths of the short-period longitudinal waves propagating in the lithosphere are about $1 / 4$ of the wavelengths of analyzed shear waves with dominant periods of $\sim 8-10 \mathrm{~s}$, on average. Therefore, the P-wave travel time deviations are more suitable to locate prominent steep boundaries in the mantle lithosphere (Fig. 5a). Such boundary, indicated beneath the NW part of the LAPNET array, can be associated with the northern half of the Baltic-Bothnia Megashear Zone (see Fig. 1) that separates the Norr-botten Craton on the west from the Karelian Craton in the east (Korja et al., 2006). Southern continuation of the BBZ is less evident in the P pattern, partly due to the lack of data at stations west of the zone. The shear-wave signal is weak there, which might reflect a more complicated geometry of the transition. In case of a gently dipping contact of two anisotropic blocks (Fig. 5b), the anisotropic signal can disappear on recordings of stations in a broader band around the surface trace of the boundary. This is observed in the $\mathrm{P}$-wave anisotropic signal 
a)
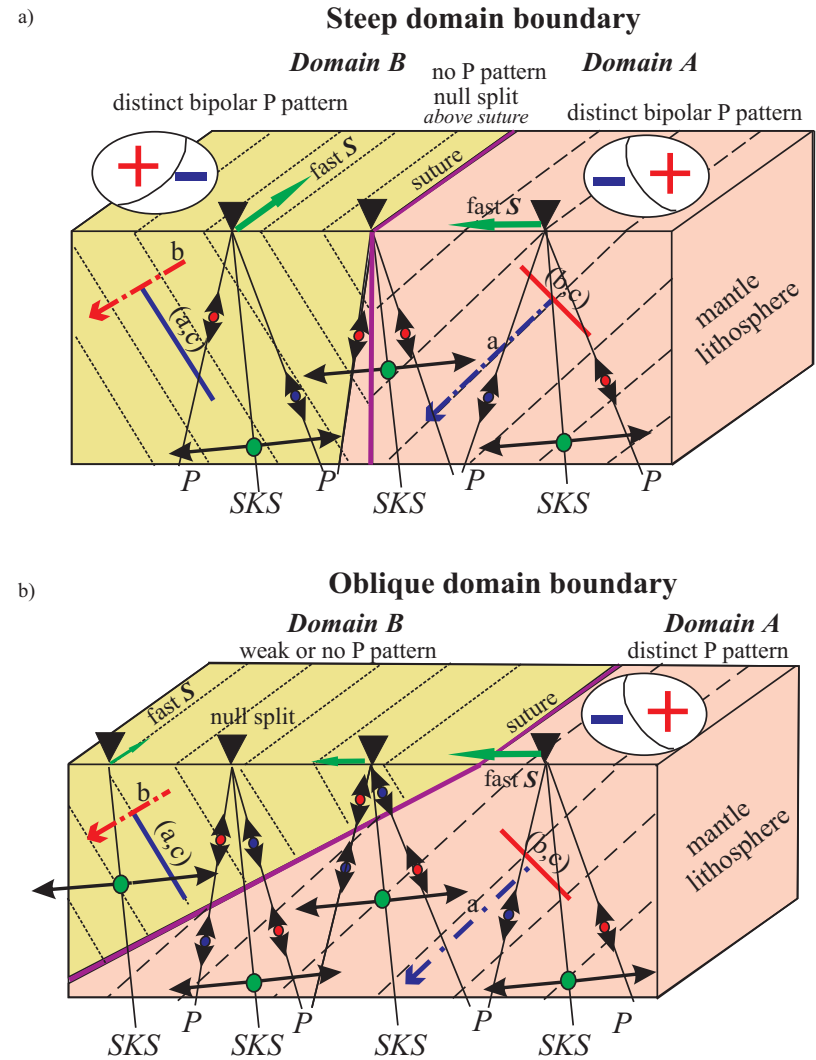

Fig. 5. Schematic fast shear-waves (long arrows perpendicular to rays) and their polarizations (green arrows) along with distribution of early (blue) and delayed (red) P-wave (short longitudinal arrows along rays) arrivals and their projection into the $\mathrm{P}$ spheres (schematic bipolar pattern shown) within two blocks with different orientation of anisotropy. Domain B is characterized by olivine aggregate with hexagonal symmetry $b$ (the $b$-axis model) and dipping high-velocity foliation $(a, c)$. Domain $\mathrm{A}$ is approximated by hexagonal aggregate with dipping lineation $a$ (the $a$-axis model). Anisotropic signal in shear waves propagating along a near vertical suture disappears (null splitting) or decreases significantly, because the waves sample both structures. If the waves travel across an inclined suture, we can detect anisotropic signal reflecting a structure, which is consistent in a volume at least comparable with the shear wavelength. The steep suture is marked by an abrupt change in the $\mathrm{P}$ sphere pattern, while the oblique suture is reflected as a broader transition with no or weak anisotropic $\mathrm{P}$ pattern.

in the south-eastern part of the LAPNET array (Fig. 2). But some stations in the very east end of the province report the strongest anisotropic signal in the shear waves in its central part, suggesting a ray path within the eastern anisotropic block was at least comparable with their wavelength, while a ray path in the western block was shorter for the particular direction of propagation. Surprisingly, the anisotropic model retrieved by the inversion of the P-wave anisotropic parameters in the west (Domain 4, Fig. 4) satisfies the evaluated shear-wave polarizations in the whole central part of the array between latitudes $\sim 66^{\circ}-68^{\circ} \mathrm{N}$, but with significant decrease of split delay times (Fig. 3).

Only coherent fabrics of the crust in a volume comparable with wave-lengths analysed, i.e., in tenths of $\mathrm{km}$, could contribute to the observed anisotropy. However, the region with the thickest crust (Grad et al., 2009) exhibits the weakest shear-wave splitting, which is contradictory. Nevertheless, we do not exclude a presence of anisotropy in the crust, particularly in the lower crust, but presumably with a symmetry axis oriented differently from the mantle and detectable at shorter wave lengths.

We observed a similar distinct decrease of anisotropic signal in a broad zone along the margin of Karelian craton at stations deployed during the SVEKALAPKO project south of the LAPNET array, which can be considered as the northward continuation of multi-disciplinary studies in Fennoscandia (Hjelt et al., 1996). The contact zone of the Archean-Proterozoic mantle lithosphere south of the LAPNET array appears as a broad zone of decreased anisotropic signal in the $\mathrm{P}$ waves and strongly direction-sensitive signal in the shear waves (Plomerová et al., 2006). Vecsey et al. (2007) modelled fabrics of the mantle lithosphere domains by 3-D self-consistent anisotropic structures with different orientations of inclined symmetry axes - either the $b$ axis models (in the Proterozoic) or the $a$-axis models (in the Archean).

Location of temporary stations in southern part of the LAPNET (2007-2009) and stations in the northern SVEKALAPKO arrays (1998-1999) overlap, which allows us to compare the anisotropic signals from independent observations (Fig. 6). The P-sphere patterns at stations KU6 and MSF in the south-eastern rim of the LAPNET array are compatible with the patterns evaluated from stations in the north-eastern rim of the SVEKALAPKO array (e.g., FH01 =MFS, FG02, FE03), though the SVEKALAPKO array operated for a shorter time ( $\sim 10$ months) and unfortunately, during a period with low teleseismic activity. The "no P-pattern" at the south-western part of the LAPNET stations has its continuation at stations in the central band of the SVEKALAPKO array (e.g., FK05) related to the Proterozoic-Archean transition zone (Plomerová et al., 2006).

Similarly to the situation at the southern end of the LAPNET array, we can compare the initial results obtained from the western part of the LAPNET array with findings of the anisotropy study beneath the Swedish National Seismological Network (SNSN, Eken et al., 2010) westward of the LAPNET array, though the end-of-stations in the north-eastern part of the SNSN did not have comparable amount of data at that time. Stations in this zone, situated most probably above the northern continuation of the Proterozoic-Archean transition in the upper mantle, do not have a clear "bipolar" $\mathrm{P}$ pattern, which could reflect fabric of a simple structure with dipping symmetry axis, indicating thus a more complex structure of the mantle lithosphere there. 


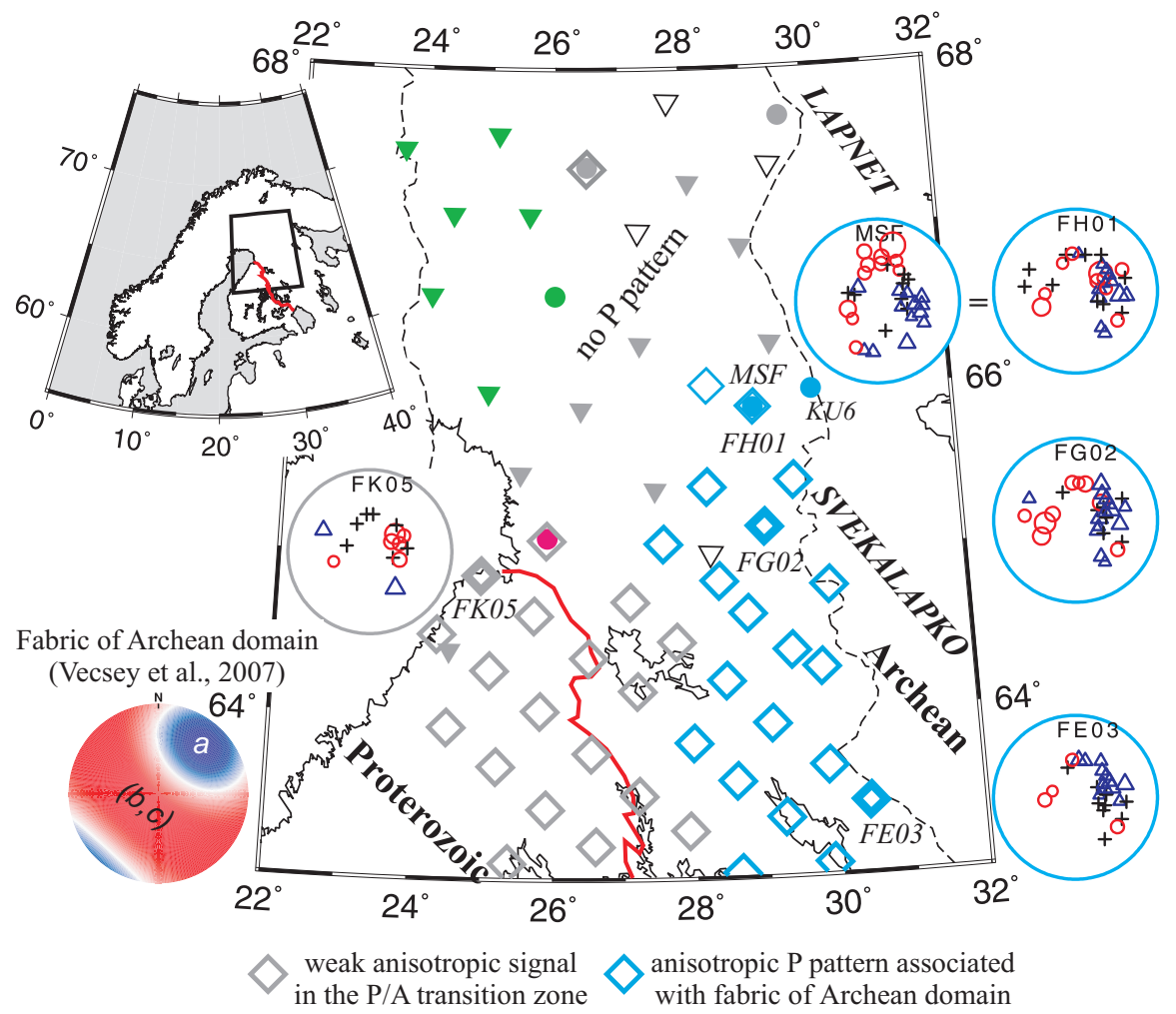

Fig. 6. Linkage of the P-sphere patterns in the southern part of the LAPNET array overlapping with the northern part of the SVEKALAPKO array. No P-pattern identified in the south-eastern part of the LAPNET array (full grey triangles and circles) concurs with the weak anisotropic signal at stations above the Proterozoic/Archean (P/A) transition zone in the upper mantle evaluated from the SVEKALAPKO data (Plomerová et al., 2006). Examples of the P-spheres for stations FH01, FG02 and FG03 of the SVEKALAPKO array in the Archean domain of Karelia (blue diamonds) show high degree of resemblance with the two south-easternmost stations of LAPNET (MSF and KU6).

Recognition of sharply bounded domains in the Archean mantle lithosphere is the most significant finding of this study of body-wave anisotropy beneath the LAPNET array, as it weakens argumentations for progressive thickening of the lithospheric roots as a result of simple cooling (e.g., Artemieva and Mooney, 2001) which would result in a horizontally structured fabric that we do not observe (Plomerová and Babuška, 2010). Based on geochemical and petrological constrains, e.g. Lee (2006) deduces that cratonic mantle may be formed by a combination of arc and oceanic lithospheric mantle accretion. Considering different composition and radioactive heat production of the crust, Gray and Pysklywec (2011) present thermo-mechanical models of Archean mantle lithosphere keels with imbricated mantle lithosphere.

To be able to model anisotropic structures of the domains reliably in 3-D, particularly inclinations of the symmetry axes, we need to process more shear-wave recordings from different back-azimuth. Nevertheless, the locations of the boundaries delimited independently from the $\mathrm{P}$ - and $\mathrm{S}$-wave anisotropy in this study is convincing. Abrupt changes of the observed body-wave anisotropy, often related to distinct tectonic sutures, or to boundaries of suspect terranes (microcontinents, Fig. 1b), allows us to associate it with fossil structure of the mantle lithosphere and not with anisotropy reflecting an olivine orientation due to the present-day flow and/or local circulations in the sub-lithospheric mantle, which is, on top of that, generally considered to be very small beneath cratons (Montagner, 1998; Pedersen et al., 2006). Assumpção et al. (2011) explain variations in average splitting parameters beneath the South America cratons by local deflections of the sub-lithospheric flow due to lithosphere thickness variations. On the other hand, Barruol et al. (2008) and Wüstefeld et al. (2010) found several arguments supporting frozen lithospheric anisotropy in cratonic areas. Mareschal and Jaupert (2006) estimate temperatures at $150 \mathrm{~km}$ depth during the Archean only $150 \mathrm{~K}$ higher that present, implying the lithosphere remains sufficiently cold and strong to preserve Archean fabrics.

In our previous studies, we modelled the domain-like structures of continental lithosphere in different European provinces, mostly of Proterozoic and younger ages (Plomerová and Babuška, 2010 for review). Vecsey et al. (2007) modelled dipping fabrics in the Archean provinces in southeastern Finland. Also, study of surface-wave polarization anisotropy suggests steeply inclined fabrics beneath Archean cratons, in general (Babuška et al., 1998). As one 
of possible mechanisms how such fabric could be formed, Babuška and Plomerová (1989) proposed a scenario based on cycles of oceanic lithosphere subductions, accretions of micro-continent fragments and a gradual stabilization of the lithosphere-asthenosphere boundary by a mantle flow after a detachment of lower parts of subducting slabs. Such plausible scenario can work in the modern plate-tectonic style. We also have to seek for explanations of the fossil fabrics observed in the Archean provinces, i.e., a fabric created at early-stage of plate tectonics or in pre-plate tectonic style (Condie and Benn, 2006). In any case, the early lithosphere formed in dynamic conditions, far from simple cooling that would produce a sub-horizontal layered structure of the lithosphere (Plomerová and Babuška, 2010).

\section{Conclusions}

Similarly to what we found in other continental regions, the mantle lithosphere of northern Fennoscandia consists of several blocks with differently oriented fabrics. We detected anisotropic signal at stations of the LAPNET array - both in the P-wave travel-time deviations and shear-wave splitting. The anisotropic parameters change across the array and stations with similar characteristics form groups. The geographical variations of seismic-wave anisotropy delimit individual domains of the mantle lithosphere, each having a consistent fabric. The domains are sharply bounded both in the Proterozoic and Archean provinces and can be modelled in 3 -D by peridotite aggregates with dipping lineation $a$ or foliation $(a, c)$. These findings allow us to interpret the domains as micro-plate fragments retaining fossil fabrics in the mantle lithosphere, reflecting thus an olivine LPO created before the micro-plates assembled, and formed in dynamic conditions far from simple cooling processes which would result in horizontally layered structures. Studies of fossil anisotropy preserved in the mantle lithosphere contribute both to mapping the lithosphere-asthenosphere boundary and deciphering the boundaries of individual blocks building the continental lithosphere.

Acknowledgements. Contributions of all members of the LAPNET working group, particularly of H. Pedersen, C. Pequegnat and E. Flin (Grenoble data centre) are greatly appreciated. The paper benefits from constructive comments of $\mathrm{M}$. Assumpção and an anonymous referee. The field work was fund by the Academy of Finland (grant No. 122762) and University of Oulu; the BEGDY program of the Agence Nationale de la Recherche, Institut Paul Emil Victor (France), task force VIII of the ILP (International Lithosphere Program); the Grant Agency of the Czech Academy of Sciences (grant No. IAA300120709) and the Geophysical Institute of the Czech Acad. of Sci., Prague; Russian Academy of Sciences (programs Nos. 5 and 9). The research of the Czech team was supported by grant No. IAA300120709 of the Grant Agency of the Academy of Sciences.

Special Issue: "The Lithosphere-Asthenosphere Boundary (LAB) Dilemma"

Edited by: U. Achauer, J. Plomerova, and R. Kind

\section{LAPNET Working Group}

Elena Kozlovskaya ${ }^{1}$, Helle Pedersen ${ }^{3}$, Jaroslava Plomerová ${ }^{6}$, Ulrich Achauer ${ }^{4}$, Eduard Kissling ${ }^{7}$, Irina Sanina ${ }^{8}$, Teppo Jämsen ${ }^{1}$, Hanna Silvennoinen ${ }^{1}$, Catherine Pequegnat ${ }^{3}$, Riitta Hurskainen ${ }^{1}$, Robert Guiguet ${ }^{3}$, Helmut Hausmann ${ }^{5}$, Petr Jedlička ${ }^{6}$, Igor Aleshin $^{10}$, Ekaterina Bourova ${ }^{3}$, Reynir Bodvarsson ${ }^{11}$, Evald Brückl $^{10}$, Tuna Eken ${ }^{6}$, Pekka Heikkinen ${ }^{2}$, Gregory Houseman ${ }^{14}$, Helge Johnsen ${ }^{12}$, Elena Kremenetskaya ${ }^{9}$, Kari Komminaho ${ }^{2}$, Helena Munzarová ${ }^{12}$, Roland Roberts ${ }^{11}$, Bohuslav Rǔžek ${ }^{6}$, Hossein Shomali ${ }^{11}$, Johannes Schweitzer ${ }^{13}$, Artem Shaumyan ${ }^{8}$, Luděk Vecsey ${ }^{6}$, Sergei Volosov ${ }^{8}$

Institutions participating in the creation of the data set

1. Sodankylä Geophysical Observatory of the University of Oulu, Finland

2. Institute of Seismology of the University of Helsinki, Finland

3. University of Grenoble, France

4. University of Strasbourg, France

5. Institute of Geodesy and Geophysics, Vienna University of Technology, Austria

6. Geophysical Institute of the Czech Academy of Sciences, Prague, Czech Republic

7. Institute of Geophysics ETH Zürich, Switzerland

8. Institute of Geospheres Dynamics of the Russian Academy of Sciences, Moscow, Russia

9. The Kola Regional Seismological Centre, of the Russian Academy of Sciences, Russia

10. Geophysical Centre of the Russian Academy of Sciences, Schmidt Institute of Physics of the Earth of the Russian Academy of Sciences, Russia

11. Swedish National Seismological Network, University of Uppsala, Sweden

12. Institute of Solid Earth Physics, University of Bergen, Norway

13. NORSAR, Norway

14. University of Leeds, UK

\section{References}

Aki, K., Christoffersson, A., and Husebye, E. S.: Determination of 3-dimensional seismic structure of lithosphere, J. Geophys. Res., 82, 277-296, 1977.

Amaru, M. L., Spakman, W., Villasenor, A., Sandoval, S., and Kissling, E. A.: new absolute arrival time data set for Europe, Geophys. J. Int., 173, 465-472, 2008.

Assumpção, M., Guarido, M., van der Lee, S., and Dourado, J. C.: Upper-mantle seismic anisotropy from SKS splitting in the South American stable platform: A test of asthenospheric flow models beneath the lithosphere, Lithosphere, 3, 173-180; doi:10.1130/L99.1, 2011.

Artemieva, I. and Mooney, W.: Thermal thickness and evolution of Precambrian lithosphere: a global study, J. Geophys. Res., 106, 16387-16416, doi:10.1029/2000JB900439, 2001. 
Babuška, V. and Plomerová, J.: Seismic anisotropy of the subcrustal lithosphere in Europe: another clue to recognition of accreted terranes? in: Deep structure and past kinematics of accreted terranes, edited by: Hillhouse, J. W., Geophys. Monograph, 50, IUGG vol. 5, Washington DC, 209-217, 1989.

Babuška, V. and Plomerová, J.: The lithosphere in central Europe - seismological and petrological aspects, Tectonophysics, 207, 141-163, 1992.

Babuška, V. and Plomerová, J.: European mantle lithosphere assembled from rigid microplates with inherited seismic anisotropy, Phys. Earth. Planet. Inter., 158, 264-280, 2006.

Babuška, V., Plomerová, J., and Šílený, J.: Models of seismic anisotropy in deep continental lithosphere, Phys. Earth Planet. Interior, 78, 167-191, 1993.

Babuška, V., Plomerová, J., and Š́lený, J.: Models of seismic anisotropy in deep continental lithosphere, Phys. Earth Planet. Interior, 78, 167-191, 1993.

Babuška, V., Montagner, J.-P., Plomerová, J., and Girardin, N.: Age-dependent large-scale fabric of the mantle lithosphere as derived from surface-wave velocity anisotropy, Pure and Appl. Geophys., 151, 257-280, 1998.

Barruol, G., Deschamps, A., Déverchère, J., Mordvinova, V. V., Ulziibat, M., Perrot, J., Artemiev, A. A., Dugarmaa, T., and Bokelmann, G. H. R.: Upper mantle flow beneath and around the Hangay dome, Central Mongolia, Earth Planet. Sci. Lett., 274, 221-233, doi:10.1016/j.eps1.2008.07.027, 2008.

Calcagnile, G.: Deep structure of Fennoscandia from fundamental and higher mode dispersion of Rayleigh waves, Tectonophysics, 195, 139-149, 1991.

Condie, K. C. and Benn, K.: Archean Geodynamics: Similar to or different from modern geodynamics? in: Archean Geodynamics and Environments, edited by: Benn, K., Mareschal, J.-C., Condie, K. C., AGU Geophysical Monograph 164, Washington, DC, 206, 47-60, 2006.

Cotte, N., Pedersen, H. A., and TOR Working Group: Sharp contrast in lithospheric structure across the Sorgenfrei-Tornquist Zone as inferred by Rayleigh wave analysis of TOR 1 project data, Tectonophysics, 360, 75-88, 2002.

Eken, T., Shomali, H., Roberts, R., and Bodvarsson, R.: Upper mantle structure of the Baltic Shield below the Swedish National Seismological Networks (SNSN) resolved by teleseismic tomography, Geophys. J. Int., 169, 617-630, 2007.

Eken, T., Shomali, Z. H., Roberts, R., Hieronymus, C.F., and Bodvarsson, R.: $\mathrm{S}$ and $\mathrm{P}$ velocity heterogeneities within the upper mantle below the Baltic Shield, Tectonophysics, 462, 109-124, 2008.

Eken, T., Plomerová, J., Roberts, R., Vecsey, L., Babuška, V., Shomali; H., and Bodvarsson, R.: Seismic anisotropy of the mantle lithosphere beneath the Swedish National Seismological Network (SNSN), Tectonophysics, 480, 241-258, 2011.

Grad, M., Tiira, T., and ESC Working Group: The Moho depth map of the European Plate, Geophys. J. Int., 176, 279-292, 2009.

Gray, R. and Pysklywec, R. N.: Geodynamic models of Archean continental collision and the formation of mantle lithosphere keels, Geophys. Res. Letters, 37, L19301, doi:10.1029/2010GL043965, 2010.

Gung, Yu., Panning, M., and Romanowicz, B.: Global anisotropy and the thickness of continents, Nature, 422, 707-711, 2003.

Hjelt, S.-E., Daly, S., and SVEKAKALAPKO colleagues:
SVEKALAPKO - evolution of Palaeoproterozoic and Archean lithosphere, in: Lithosphere Dynamics, Origin and Evolution of Continents, edited by: Gee, D. G., Zeyen, H. J., Uppsala University, 57-67, 1996.

Korja, A., Lahtinen, R., and Nironen, M.: The Svekofennian orogen: a collage of microcontinents and island arcs, In: European Lithosphere Dynamics, edited by: Gee, D. G. and Stephenson, R. A., Geol. Soc. London, Memoirs, 32, 561-578, 2006.

Kozlovskaya, E. and the POLENET/LAPNET Working Group: Analysis of glacial seismic events from Greenland recorded by the POLENET/LAPNET experiment during the IPY 2007-2009. EGU General Assembly, Vienna, Austria, 3-8 April 2011, Geophysical Research Abstracts 13, EGU2011-8322, 2011.

Lee, C.-T. A.: Geochemical/petrological constraints on the origin of cratonic mantle, in: Archean Geodynamics and Environments, edited by: Benn, K., Mareschal, J.-C., Condie, K. C., AGU Geophysical Monograph 164, Washington, DC, 206 pp., 89-114, 2006.

Luosto, U.: Structure of the Earth's crust in Fennoscandia as revealed from refraction and wide-angle reflection studies, Geophysica, 33, 3-16, 1997.

Mareschal, J.-C. and Jaupert, C.: Archean thermal regime and stabilization of cratons, in: Archean Geodynamics and Environments, edited by: Benn, K., Mareschal, J.-C., Condie, K. C., AGU Geophysical Monograph 164, Washington, DC, 206 pp., 61-73, 2006.

Mitterbauer, U., Behm, M., Brückl, E., Lippitsch, R., Guterch, A., Keller, R., Koslovskaya, E., Rumpfhuber, E-M., and Šumanovac, F. : Shape and origin of the East-Alpine slab constrained by the ALPASS teleseismic model, Tectonophysics, 510, 195-206, 2011.

Montagner, J.-P.: Where can seismic anisotropy be detected in the Earth's mantle? in: Boundary Layers, Pure Appl. Geophys., 151, 223-256, 1998.

O'Driscoll, L. J., Humpreys, E. D., and Schmandt, B.: Time corrections to teleseismic $\mathrm{P}$ delays derived from SKS splitting parameters and implications for western US P-wave tomography, Geophys. Res. Lett., 38, L19304, doi:10.1029/2011GL049031, 2011.

Olsson, S.: Analyses of seismic wave conversion in the crust and upper mantle beneath the Baltic Shield, Digital Comprehensive Summaries of Uppsala Dissertations from of Science and Technology 319, Acta-Universitatis-Upsaliensis-Uppsala, ISBN: 978-91-554-6919-1, 2007.

Pedersen, H. A., Bruneton, M., Maupin, V., and SVEKALAPKO STWG: Lithospheric and sublithospheric anisotropy beneath the Baltic Shield from surface wave array analysis, Earth Planet. Sci. Lett., 244, 590-605, 2006.

Poutanen, M. and Ivins, E. R.: Upper mantle dynamics and quaternary climate in cratonic areas (DynaQlim)-Understanding the glacial isostatic adjustment, J. of Geodynamics, 50, 2-7, 2010.

Plomerová, J. and Babuška, V.: Long memory of mantle lithosphere fabric - European LAB constrained from seismic anisotropy, Lithos, 120, 131-143, 2010.

Plomerová, J., Arvidsson, R., Babuška, V., Granet, M., Kulhánek, O., Poupinet, G., and Š́lený, J.: An array study of lithospheric structure across the Protogine zone, Varmland, south-central Sweden - signs of a paleocontinental collision, Tectonophysics, 332, 1-21, 2001. 
Plomerová, J., Babuška, V., Vecsey, L., Kouba, D., and TOR Working Group: Seismic anisotropy of the lithosphere around the Trans-European Suture Zone (TESZ) based on teleseismic bodywave data of the TOR experiment, Tectonophysics, 360, 89-114, 2002.

Plomerová, J., Babuška, V., Vecsey, L., Kozlovskaya, E., Raita, T., and SSTWG: Proterozoic-Archean boundary in the upper mantle of eastern Fennoscandia as seen by seismic anisotropy, J. Geodyn., 41, 400-410, doi:10.1016/j.jog.2005.10.008, 2006.

Plomerová, J., Babuška, V., Kozlovskaya, E., Vecsey L., and Hyvonen, L.,T.: Seismic anisotropy - a key to resolve fabrics of mantle lithosphere of Fennoscandia, Tectonophysics, 462, 125-136, 2008.

Rawlinson, N. and Kennett, B. L. N.: Rapid estimation of relative and absolute delay times across a network by adaptive stacking, Geophys. J. Int., 157, 332-340, doi:10.1111/j.1365246X.2004.02188.x, 2004.

Ritter, J. R. R., Jordan, M., Christensen, U. R., and Achauer, U.: A mantle plume below the Eifel volcanic fields, Germany, Earth Planet. Sci. Lett., 186, 7-14, 2001.

Sandoval, S., Kissling. E., and Ansorge, J.: High-resolution body wave tomography beneath the SVEKALAPKO array: II. Anomalous upper mantle structure beneath the central Baltic Shield, Geophys. J. Int., 157, 200-214, 2004.

Shomali, Z. H., Roberts, R. G., Pedersen, L. B., and the TOR Working Group: Lithospheric structure of the Tornquist Zone resolved by nonlinear $\mathrm{P}$ and $\mathrm{S}$ teleseismic tomography along the TOR array, Tectonophysics, 416, 133-149, 2006.

Snyder, D. B.: Lithospheric growth at margins of craton. Tectonophysics, 355, 7-2, 2002.
Šílený, J. and Plomerová, J.: Inversion of shear-wave splitting parameters to retrieve three-dimensional orientation of anisotropy in continental lithosphere, Phys. Earth. Plant. Int., 95, 277-292, 1996.

Silvennoinenn, H., Kozlovskaya, E., Kissling, E., Janik, T., and the POLENET/LAPNET Working Group: Compilation of initial 3D crustal model northern Fennoscandian shield, Geophysical Research Abstracts 13, EGU2011-9968, 2011.

Stammler, K.: Seismichandler programmable multichannel data handler for interactive and automatic processing of seismological analyses, Comp. Geosci., 19, 135-140, 1993.

Uski, M., Tiira, T., Korja, A., and Elo, S.: The 2003 earthquake swarm in Anjalankoski, south-eastern Finland, Tectonophysics, 422, 55-69, 2006.

Vecsey, L., Plomerová, J., Kozlovskaya, E., and Babuška, V.: Shearwave splitting as a diagnostic of varying upper mantle structure beneath south-eastern Fennoscandia, Tectonophysics, 438, 5777, 2007.

Vecsey, L., Plomerová, J., and Babuška, V.: Shear-wave splitting measurements - problems and solutions, Tectonophysics, 462, 178-196, doi:10.1016/j.tecto.2008.01.021, 2008.

Vecsey, L., Plomerová, J., Eken, T., and Babuška, V.: Role of seismic anisotropy in isotropic tomographic models of the upper mantle, Geophysical Research Abstracts Vol. 13, EGU20113164, 2011.

Wüstefeld, A., Bokelmann, G., and Barruol, G.: Evidence for ancient lithospheric deformation in the East European Craton based on mantle seismic anisotropy and crustal magnetics, Tectonophysics, 481, 16-28, 2010. 